\title{
Design analysis of a hot strip mill runout table bed under ANSYS workbench
}

\author{
Sudhansu Mohan Padhy ${ }^{l}$, Rudrajit Sinha ${ }^{1 *}$, Ruby Mishra ${ }^{1}$, Purna Chandra Mishra ${ }^{l}$ \\ ${ }^{1}$ School of Mechanical Engineering, Kalinga Institute of Industrial Technology Deemed to be University, Bhubaneswar-24, India
}

\begin{abstract}
A structural analysis has been performed on the setup of a spray cooling system for a model of a hot strip mill. The objective was to design a run out table (ROT) whose length is reduced for a spray cooling system. The setup consists of a bed (ROT) whose height can be adjusted as desired, and a carriage which would be carrying the hot plate, moving along the bed, for experimentation. The CAD modelling was done in CATIA and the analysis was performed in ANSYS Workbench. A prototype of the whole setup was built from the virtual model and was controlled using products from National Instrument Corporation (NI). The analysis is being conducted for the design optimization of the entire setup and its safety.
\end{abstract}

\section{Introduction}

The run-out table (ROT) in a hot strip mill is the place where the process of ultra-fast cooling takes place. [1] The hot strip manufactures coils of the required gauges from a slab of unknown dimensions and chemical composition. A ROT generally consists of a bed through which the hot strip moves, and an array of cooling nozzles that cools down the strip itself. Ultra-fast cooling is done by using a high flow of water and air. Cooling methods include curtains of jets, spray, circular jet, etc. A new design for the bed of the run-out table has been developed which has a degree of freedom in the $\mathrm{Y}$-axis. A carriage has also been designed and developed to carry the plate/work piece $[1,2,4$,$] at 850$ to $900{ }^{\circ} \mathrm{C}$ moving along the bed, having and horizontal motion.

According to most researchers, [3] controlled cooling of the strips is required to attain a high grade of rolled steel which is important in industries such as automobile, construction and house-appliances. A. Suebsomran et al. [4] conducted a study to determine the effective cooling parameters for the run-out table (ROT) of strip steel in a hot rolling process by developing the 2-dimensional transient heat transfer of strip steel by using a mathematical model. R.-M. Guo [5] made a simple control algorithm for the run-out table cooling control based on a mathematical model which can deactivate and activate the cooling headers at any point that also uses a tracking system to monitor the temperature control. The length of the bed has been reduced to make the setup as compact as possible. In a traditional mill, [6] the values for strip thickness, temperature and strip thickness are given as input but in the ROT, [7] the material is cooled by arrays of the top and bottom cooling headers in a distance of about $70 \%$ of the run-out table length. [8] Usually, spray cooling is used for roll cooling or descaling of the plate's surface, and jet cooling is used for plate cooling since it can effectively transport its momentum to the plate's surface. [9] The cooling process contains a lot of complex physics which can be difficult to solve, due to which, studies of the problem have been largely restricted to experimental methods. After the cooling process, [10] the microstructure of the metal defines its mechanical physical properties. [11] NKK's Fukuyama Works completed installing a SuperOLAC H (on-line accelerated cooling for hot strip mill) system at the runout cooling zone of its No. 1 hot strip mill, which had a length of $30-45 \mathrm{~m}$ and was able to achieve a cooling rate of $700{ }^{\circ} \mathrm{C} / \mathrm{s}$ for a sheet of thickness of $3 \mathrm{~mm}$.

This design is meant as a laboratory setup to perform experimental studies. The objective of this work is to analyse the effect of the load of the carriage and plates of two different thicknesses on the bed using ANSYS Workbench so as to find any flaw in the design and optimize it accordingly.

\subsection{Modelling of the bed in runout table}

The design model created in CATIA software environments consists of a horizontal bed and a carriage, as shown in Fig.1, which are the major components of the whole setup. The bed is made of flat plates $4 \mathrm{~mm}$ thick and is $1.7 \mathrm{~m}$ long in length. It is supported by two hollow cylindrical rods of $50 \mathrm{~mm}$ in diameter. The bed is supported by rollers so as to have a vertical motion. The created vertical motion of the whole bed enables experiments to be conducted with different settings.

\footnotetext{
$\bar{*}$ Rudraiit Sinha: rudraiit94@,gmail.com
} 


\subsection{Methodology}

\subsubsection{Simulation in ANSYS Workbench}

The structural analysis is done in ANSYS Workbench under static structural, where a force of $2 \mathrm{~N}$, which simulates the maximum force that will be applied on the carriage by the spray and the force due to the weight of the carriage is applied on the plate. The analysis has been performed for three different positions of the carriage on the bed. Plates of two different thicknesses (4 $\mathrm{mm}$ and $10 \mathrm{~mm}$ ) have been used [12].

\subsubsection{Development of Automated ROT}

The prototype of the whole setup built from the virtual model was controlled using NI Instrumentation. A LabVIEW based programme was developed for the wireless control of carriage motion in the ROT. Under the LabVIEW programme, the speed of the carriage movement is controlled through MyRIO which in turn controls the stepper motor of the carriage. The Virtual Interface (VI) of the LabVIEW programme is depicted in Fig. 3. The carriage was designed and created to carry a hot metal plate, which would be cooled by spraying nozzles containing internally mix cooling fluids fitted onto an aluminium frame above.

\section{Simulation parameters and results}

\subsection{The parameters for the analyses}

The structural analysis of the setup was performed by conducting a series of 6 simulations with different parameters. The parameters consist of three different positions, $300 \mathrm{~mm}, 750 \mathrm{~mm}, 1200 \mathrm{~mm}$, from the vertical rods and two different flat plates of thickness, $4 \mathrm{~mm}$ and $10 \mathrm{~mm}$. The three positions were taken according to the movement range of the carriage.

The meshing for the whole setup was done with the auto-mesh feature of ANSYS Workbench. The mesh was a tetrahedral type of mesh for the whole setup as can be seen in Fig 2.

Table 1 shows the parameters taken for the analyses that have been simulated in ANSYS:

Table 1. Analyses Performed.

\begin{tabular}{|c|c|c|}
\hline Sl. No. & $\begin{array}{c}\text { Distance of the } \\
\text { carriage from the } \\
\text { vertical rods (D) } \\
\text { (mm) }\end{array}$ & $\begin{array}{c}\text { Plate thickness } \\
\text { (t) (mm) }\end{array}$ \\
\hline 1 & 300 & 4 \\
\hline 2 & 750 & 4 \\
\hline
\end{tabular}

\begin{tabular}{|l|l|l|}
\hline 3 & 1200 & 4 \\
\hline 4 & 300 & 10 \\
\hline 5 & 750 & 10 \\
\hline 6 & 1200 & 10 \\
\hline
\end{tabular}

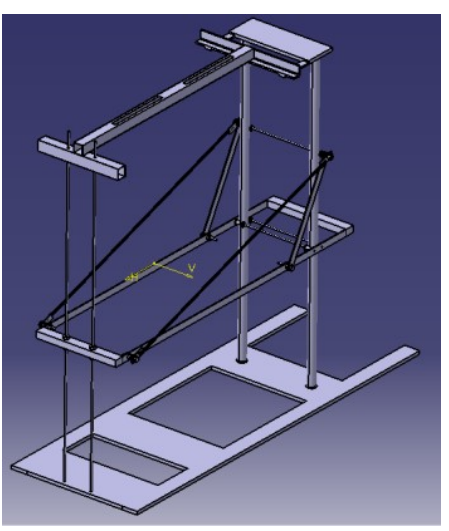

Fig. 1. The model of the whole setup consisting of the bed and the carriage modelled in CATIA.

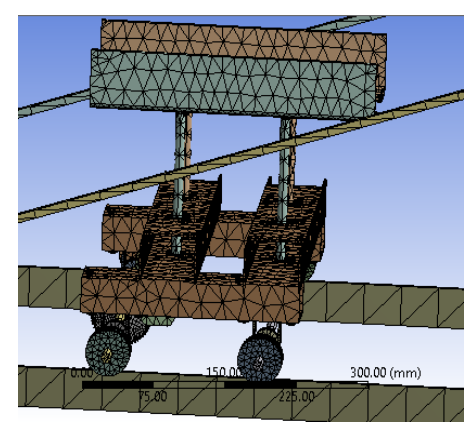

Fig. 2. The tetrahedral mesh used for the simulations.
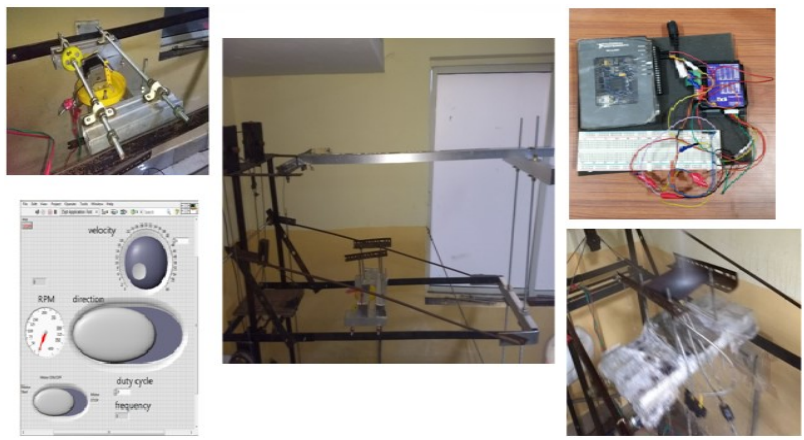

Fig. 3. The prototype controlled using MyRIO and LabVIEW. 


\subsection{Results and discussion}

A force of $55 \mathrm{~N}$ and $65 \mathrm{~N}$ has been calculated and used for the simulation and the base is taken as the fixed support and for the solution, the maximum deformation, the maximum equivalent von-mises stress and the maximum principal stress was found.

From Figs. 4, 5 and 6 the maximum deformation was found at analysis no. 5 (Table 1) where the carriage is at a distance of $750 \mathrm{~mm}$ from the vertical rods, which is at the middle of the bed, carrying a $10 \mathrm{~mm}$ thick plate and a force of $65 \mathrm{~N}$ is used in the simulation.

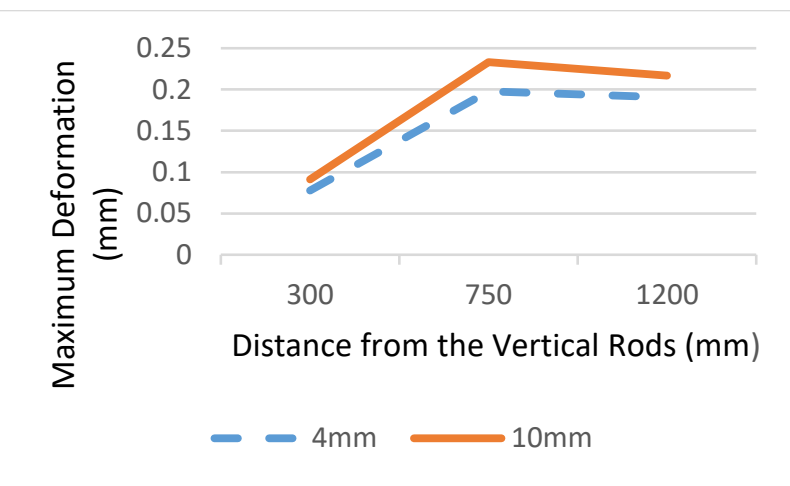

Fig. 4. The graphical representation of Maximum Deformation

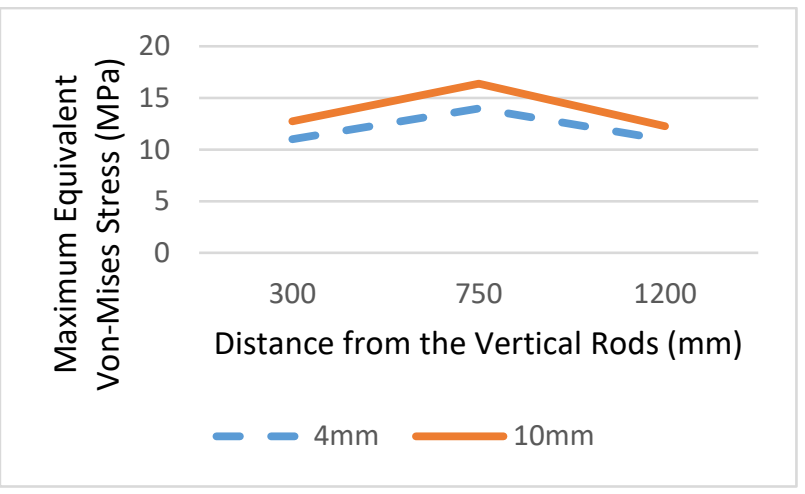

Fig. 5. The graphical representation of Maximum Equivalent Von-Mises Stress

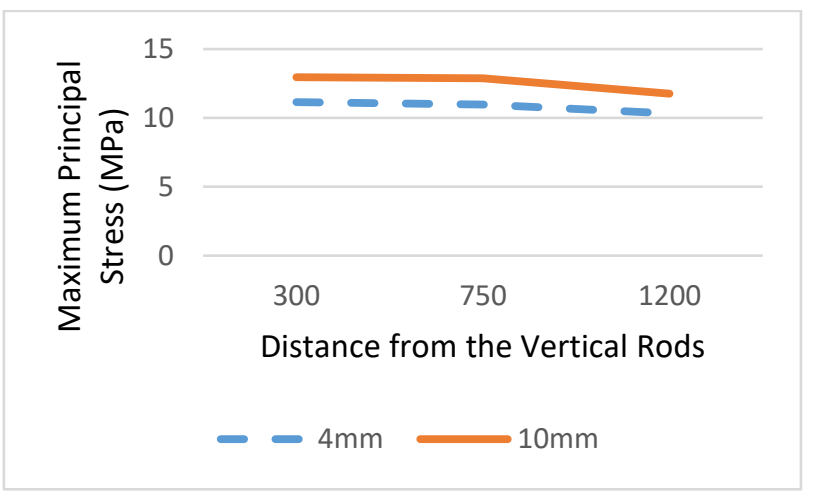

Fig. 6. The graphical representation of Maximum Principal Stress

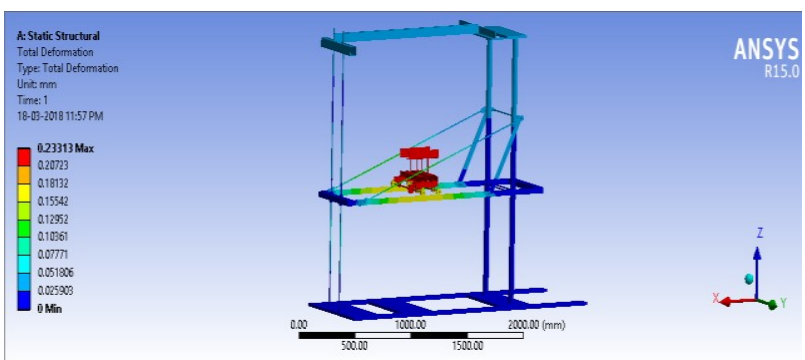

Fig. 7. The Maximum Deformation for the analysis no. 5

\subsection{The effect of the force on the bed}

The values for the maximum deformation were obtained using probes on the bed in the most deformed region as shown in Fig. 9 for each set analysis.

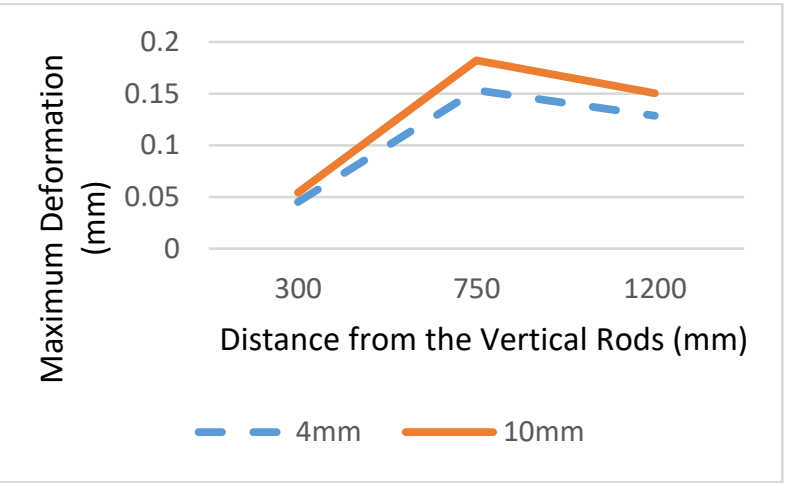

Fig. 8. The graphical representation of Maximum Deformation on the bed

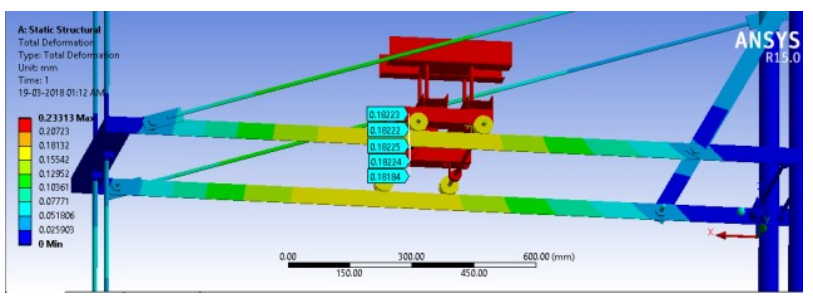

Fig. 9. The Maximum Deformation on the Bed.

\section{Calculations}

The Forces used in the analyses were calculated using the weights of the carriage and the two different plates.

Weight of the Carriage $=4.515 \mathrm{~kg}$

Weight of $4 \mathrm{~mm}$ plate $=0.455 \mathrm{~kg}$

Weight of $10 \mathrm{~mm}$ plate $=1.15 \mathrm{~kg}$

Carriage $+4 \mathrm{~mm}=4.97 \mathrm{~kg} \approx 5 \mathrm{~kg}$

Force $=5 \times 9.81=49.05 \mathrm{~N}$

Carriage $+10 \mathrm{~mm}=5.665 \mathrm{~kg} \approx 5.7 \mathrm{~kg}$

Force $=5.7$ X $9.81=55.917 \mathrm{~N}$

Since the plate is subjected to spray cooling, a force is also exerted on the plate from the spray. It is calculated using formulas for impact of jets on a surface normal to it and the Bernoulli's equation. 
The force from jet:

Bernoulli's equation states that -

$$
p+\frac{1}{2} \rho V^{2}+\rho g h=\text { constant }
$$

Where,

$\rho=$ the density of the fluid,

$\mathrm{p}=$ the pressure,

$\mathrm{V}=$ the velocity,

$\mathrm{h}=$ elevation,

$\mathrm{g}=$ gravitational acceleration

Now,

$g h_{2}$

$$
\frac{p_{1}}{\rho}+\frac{V_{1}^{2}}{2}+g h_{1}=\frac{p_{2}}{\rho}+\frac{V_{2}^{2}}{2}+
$$

$g h_{1}=0$ as the elevation is zero

$V_{1}=0$ (initial velocity) and $V_{2}=V$

$$
\sqrt{2\left[\left(\frac{p_{1}-p_{2}}{\rho}\right)-h_{2} g\right]}
$$

Taking the pressure as $0.5 \mathrm{MPa}$, density as $1000 \mathrm{~kg} / \mathrm{m}^{3}$ and height as $100 \mathrm{~mm}$

We get $V=31.65 \mathrm{~m} / \mathrm{s}$

Solving the Bernoulli's equation we get the velocity of the jet and then we use it to find the force exerted by the jet.

Dynamic forces exerted by fluid on plate normal to jet:

$$
\begin{aligned}
& \qquad F_{x}=\rho a V^{2} \\
& \rho=\text { density of water }=1000 \mathrm{~kg} / \mathrm{m}^{3} \\
& \mathrm{a}=\text { area of the mouth of the nozzle } \\
& \text { Diameter of the nozzle }=1.5 \mathrm{~mm}
\end{aligned}
$$

$$
\begin{gathered}
=10^{3} X \frac{\pi}{4} X\left(1.5 \times 10^{-3}\right)^{2} \times 31.65^{2} \\
=1.77 \mathrm{~N} \approx 2 \mathrm{~N}
\end{gathered}
$$

The above calculation is for a water jet on a plate normal to it and considering that the force from a water spray would be much less we take the value of the force as $2 \mathrm{~N}$ for the analysis.

Total force, $F_{1}$ (with $4 \mathrm{~mm}$ plate) $=51.05 \mathrm{~N} \approx 55 \mathrm{~N}$

Total force, $F_{2}$ (with $10 \mathrm{~mm}$ plate) $=61.91 \mathrm{~N} \approx 65 \mathrm{~N}$

\section{Conclusion}

A simple set of analyses were performed on the setup model using ANSYS Workbench. The advantage of this setup is that it requires lesser space due to the fact that the length of the bed has been reduced. Nozzles are placed on the aluminium frame on the top of the setup, and the hot plates are cooled using a spray mixture of water and air. The movement of the carriage in the prototype setup was controlled wirelessly with the help of MyRIO and LabView, which gives a greater advantage as one can observe and control the whole process of the cooling from a faraway distance. The results show that the maximum deformation formed on the bed is $0.182 \mathrm{~mm}$, which can be considered as negligible for the different types of experiment being conducted on the whole setup. Therefore, the whole setup needs no optimization but if required, supports can be introduced on the bed at a distance of $750 \mathrm{~mm}$ from the vertical rods.

\section{References}

1. Z. Liu, Experiments and Mathematical Modelling of Controlled Runout table Cooling in a Hot Rolling Mill, The University of British Columbia, Department of Metals and Materials Engineering, (2001)

2. A. Suebsomran, S. Butdee, The Study of Cooling Process on Runout Table by Simulation Method, ISRN Industrial Engineering, 2013, 7 (2013)

3. V. H. Hernandez- A Vila, Heat Transfer Model of the Hot Tolling Runout Table-Cooling and Coil Cooling of Steel, The University of British Columbia, Department of Metals and Materials Engineering, (1994)

4. A. Suebsomran, S. Butdee, Cooling process on a run-out table by the simulation method, Case Studies in Thermal Engineering, 1, 51-56, (2003)

5. R.-M. Guo, Modeling and Simulation of Run-Out Table Cooling Control Using Feed forwardFeedback and Element Tracking System, IEEE Transactions On Industry Applications, 33, (March/April 1997)

6. S. K. Yildiz, J. F. Forbes, B. Huang, Y. Zhang, F. Wang, V. Vaculik, M. Dudzic, Dynamic modelling and simulation of a hot strip finishing mill, Applied Mathematical Modelling, 33, 3208-3225, (2009)

7. R.-M. Guo, Heat transfer of laminar flow cooling during strip acceleration on hot strip mill run-out tables, Trans. ISS-AIME, 8, 49-59, (Aug. 1993)

8. M. J. Kwon, I. S. Park, Nozzle Arrangement for Optimal Performance of Cooling Process of Run Out Table, ISIJ International, 53, 2192-2196, (2013)

9. I. S. Park, Numerical Analysis for Film Boiling Heat Transfer of a Moving Hot Steel Plate, ISIJ International, 51, 743-747, (2011)

10. M. Hadjiysky, M. Petkova, Multimodel Based Constrained Predictive Control of Hot Strip Mill Runout Table, IFAC Proceedings Volumes, 31, 817822 (1998)

11. T. Ohashi, Production and Technology of Iron and Steel in Japan during 2002, ISIJ International, 43, 957-974, (2003)

12. S. K. Nayak, P. C. Mishra, S. K. S. Parashar, Influence of spray characteristics on heat flux in dual phase spray impingement cooling of hot surface, Alexandria Engineering Journal, 55, 19952004, (2016). 